\title{
Overcoming the barriers to the innovations diffusion through diffusion-oriented policies. The case of Li-Ion Battery for Electric Vehicles *
}

\author{
ILARIA TUTORE ${ }^{*}$ MARCO FERRETTI ${ }^{* *}$ MICHELE SIMONI ${ }^{* *}$
}

\begin{abstract}
Purpose of the paper: The paper aims at developing a theoretical framework that links diffusion policies to the types of barriers to which theoretical models of diffusion of innovation implicitly or explicitly refer.

Methodology: The conceptual framework is based on an extended literature review. The model is applied to an empirical case: the technology policy applied to diffuse the Li-Ion battery for electric vehicles.

Findings: Literature has deeply analysed the policies for the development of innovations, but analysed the policies for innovations diffusion much less. To fill this gap, the study highlights that an effective approach to the diffusion of a new technology should be based on a careful analysis of the barriers to such diffusion and on a set of policies that simultaneously act on these barriers.

Research limits: Additional empirical studies are required to assess the applicability of the proposed conceptual framework.

Practical implications: The conceptual framework of this paper has implications for scholars and policy makers. For scholars the paper opens the path towards the deepening of a subject that is still little studied. For policy makers the research provides a conceptual tool to guide their choices in supporting the diffusion of relevant technologies.

Originality of the paper: The paper classifies the barriers to the diffusion of a new technology, providing a different perspective on theoretical studies on the diffusion of innovations. It proposes a theoretical framework that links policies supporting the

- The paper is the result of the joint efforts of the Authors. In particular, Ilaria Tutore has written the following paragraphs: 5, 6; Marco Ferretti has written has written the following paragraphs: 1, 2; Michele Simoni has written has written the following paragraphs: 3,4 .

The autors acknowledge the financial support of the National Interest Research Program (PRIN 2009) "Linee di intervento a supporto dei processi di diffusione delle innovazioni nei settori del Made in Italy".

* Research Fellow - University of Naples "Parthenope"

e-mail: ilaria.tutore@uniparthenope.it

** Associated Professor - University of Naples "Parthenope"

e-mail: marco.ferretti@uniparthenope.it

*** Associated Professor - University of Naples "Parthenope"Parthenope"

e-mail: michele.simoni@uniparthenope.it
\end{abstract}


dissemination of an innovation to the diffusion barriers for the first time. The potential explanatory power of the model is verified through a concrete case study.

Key words: diffusion of innovation; barriers to diffusion; diffusion policies; lithium batteries; electric cars

\section{Introduction}

The diffusion of innovation (DOI) is topic of interest for a large range of disciplines. The phenomenon, approached from several different points of view, has been described as "the process by which an innovation is communicated through certain channels over time among members of social system" (Rogers, 1995, p.5). Many sociologists make a distinction between the words "innovation" and "technology"; they define an innovation as an idea or object that is perceived as new by an individual, and technology as a design for instrumental action.

More specifically, technological diffusion is defined as the "process by which innovations (new products, new processes, new management methods) spread within and across economies" (Stoneman, 1976). Rogers (1995) stressed that since most new ideas are technological innovations, it is meaningful to treat innovation and technology as synonyms.

Studies on DOI address relevant issues about the characteristics, determinants and effects of the adoption process (Antonelli, 2006). In particular, scholars have attempted to understand why adoption and later diffusion are not instantaneous and all firms do not adopt the innovation at the same time (Stoneman, 1976). Different models have been provided in order to better understand the diffusion of innovation. Generally, these models focus on diffusion delays, analyzing the factors that affect the diffusion process (Goldfarb, 2005).

Although literature on innovation technology has analyzed how this diffusion process occurs over time in depth, only few studies explicitly focused on the role covered by technology policy in speeding up the diffusion process.

Generally, policy initiatives have tried to concentrate mainly on the attempt to generate and exploit technology invention or innovation. Technology policy questions, as highlighted by Dasgupta and Stoneman (2005), are all related to technology generation, leaving out the dissemination dimension of new technology (Hahn and Yu, 1999). On the contrary, diffusion-oriented policy (Chiang, 1991) aims at promoting the acquisition, diffusion and assimilation of a new technology in a certain determined industry.

Ergas (1987) specified that the first priority in setting technology policies is to ease the constraints and rigidities which slow the diffusion of new skills, technical capabilities and the later technological innovation. These barriers represent an extra cost for adopters that can stop or shape the innovation process (Budunchi and Smart, 2010). 
For this reason it could be useful to recognize the main rigidities that impede or slow down diffusion processes in order to identify which diffusion policy could be used to reduce the effects of such extra costs.

In accordance with these considerations, the aim of the paper is to provide a theoretical framework that classifies technology policies according to the different barriers to the diffusion of innovation that they intend to reduce.

Contributions to literature on our theoretical framework are manifold. First the framework provides a comprehensive view of various diffusion policies, filling the gap in innovation management studies that are mainly focused on "missionoriented" policy.

Secondly, the study deepens the understanding of the role of technology policy in reducing the costs of innovation diffusion. From a theoretical perspective this allows scholars to develop a research agenda that considers the role of technology policies that may foster a massive adoption of an innovation within an industry. From a practical point of view the framework allows managers and policy makers to turn their attention to diffusion costs when setting policies aimed at overcoming barriers to innovation diffusion.

The paper starts by examining the literature on technological policy diffusion; the second part explores the main barriers to the diffusion of innovation; in the third part, technology policy and its barriers are combined in a comprehensive theoretical framework that will be tested through an empirical case: the technology policy adopted to favor the market introduction of Li-Ion battery powered vehicles.

\section{The idea of technology policy}

Technology policy can be defined as that designed and/or implemented to affect the innovative performance of a nation and/or of specific industries by influencing the decision to develop, commercialize and/or adopt new technologies (Mowery, 1995; Hahn and Yu, 1999). Technology policy can come both from governments and from technology suppliers: the main purpose of these policies is to spread technological capabilities throughout the industrial structure, thus facilitating the ongoing and the incremental adaptation to change (Ergas, 1987).

In past years, economic literature on technology and public policy has focused predominantly on generation policies, underestimating the effects of policy interventions in the diffusion process. However, some scholars have also started to consider the relevance of policies aimed at sustaining the diffusion of a new technology (Chiang, 1991; Stoneman and Diederen, 1994; Hahn and Yu, 1999; Caerteling et al., 2008). Indeed, according to Ergas (1987) technology policies should be more oriented towards ensuring effective technology utilization than stimulating new ideas. The author proposed a specific taxonomy to classify the two different policies: the "mission-oriented" policy aimed at generating new ideas and encouraging R\&D, and the "diffusion-oriented" policy, more focalized on spreading such innovations. 
Specifically, the "diffusion oriented" policy focuses on technology acquisition, diffusion and adaptation, as it spins on or trickles up existing products and industries (Chiang, 1991).

On the other hand, Hahn and Yu (1999) suggested that technology generation and diffusion policies are cyclical since technology change must be analysed as a whole rather than separated parts of invention, innovation and diffusion. They argue that there exists a bi-directional and cyclical linkage between these policies: policies aimed at technology generation could improve technology diffusion and vice-versa (Hahn and $\mathrm{Yu}, 1999$ ).

Policy issues are important in technology matters because the market for technology is imperfect (Hahn and $\mathrm{Yu}, 1999)$. As Arrow (1962) suggested, the incomplete appropriability of technology refers to the fact that invention or innovation (or more generally knowledge and information) have some of the public goods' characteristics, which provides preliminarily evidence of market failure and therefore causes -for example- the need for government intervention (Hahn and $\mathrm{Yu}$, 1999).

Stoneman and Diederen (1997) envisaged three main sources of market failure: imperfect information, market power and externalities.

Information asymmetries represent the first source of market failure. In order to reduce the inaccuracy of technology expectation, policy intervention is desirable to the point where the marginal benefit of information provision is equal to the marginal cost of that intervention: both private and public policies allow a better diffusion process that is not necessarily the fastest one. The second source of market failure is represented by the market structure, but there is no clear prediction in the literature about which market structure will generate optimal diffusion. Finally, externalities are the third main source of market imperfection. Negative externalities occur if the adoption of technology by one firm negatively affects all other firms, where the effect of these impacts is not being accounted in the adoption choice.

The rationale part of technology policies is based on these market imperfections. In cases where imperfections make its intervention necessary, the central Government represents an important catalyst in the process of innovation and diffusion by using a wide range of policies it plays the role of technology sponsor and diffuser.

As a matter of fact, the role of Governments in the development and enhancement of innovative performance in economies is widely recognized.

Following the assumption of "endogenous growth" proposed by Romer (1994), according to which "economic growth is an endogenous outcome of an economic system, not the result of forces that impinge from outside"(Romer, 1994, p. 3), policy makers cover a key role in stimulating the rate of R\&D activities and the diffusion of innovations in order to enforce national competitiveness. 


\section{A theoretical model of the barriers to new technologies diffusion}

Diffusion theories have their origins in the explanation of the adoption of technological change by farmers (Rogers, 1995). Since then, the scope of diffusion theories and associated empirical research has broadened (Nutley et al., 2002) to include education, anthropology, geography and sociology, believed to complement one another (Kelly, 1978). Indeed, "diffusion is a complex social phenomenon which clearly involves both economic and non-economic factors" (Warner, 1974, p.438).

Studies on DOI address relevant questions about the characteristics, determinants and effects of the adoption process (Antonelli, 2006). In particular, scholars have attempted to understand why diffusion and later adoption are not instantaneous and why all firms do not adopt the innovation at the same time (Stoneman, 1976).

Using different perspectives, several approaches have been developed in order to analyze how this diffusion process occurs over time, which factors affect the diffusion pattern and why adopters choose a specific technology.

While a number of literature reviews (Baptista, 1999; Geroski, 2000; Meade and Islam, 2006) offer a clear understanding of the rationale behind each model of innovation diffusion, none of them systematizes an aspect that is common to all theories: i.e. the constraints that each theory considers as inhibiting innovation diffusion

For this reason, an important step towards developing a comprehensive framework of technology policy starts with the study of the different kinds of barriers that each model of innovation diffusion has explicitly or implicitly assumed to be a driver of the phenomenon. Indeed, the identification of these barriers is a key issue, as they can stop or shape the innovation process (Budunchi and Smart, 2010). These barriers are considered as an extra-cost for adopters that slows down the diffusion process

We have identified distinct categories of costs specifically stressed in each stream of research.

The most relevant models belong to the epidemic approach (Griliches, 1957, Mansfield, 1961; Bass, $1969^{1}$ ) where diffusion is the result of information diffusion (Baptista, 1999).

The main outcome of this model is that when the number of users of a new product or invention is plotted versus time, it allows the development of the typical S-shape curve of diffusion. Similarly, it is represented as a bell-shape curve when frequency is plotted over time.

According to this approach, the aggregate model of diffusion depends on the frequency of contact between potential and actual users. The information flows among parties lead to an epidemic effect on the rate of technological diffusion (Bocquet et al., 2007).

Bass (1969) applied the model to consumer products, revealing the double effect of two means of communication: mass media and word of mouth. 
In these models the role of information is emphasized by technology spillover or word of mouth among potential users.

Epidemic models consider that the diffusion of a new technology is the result of the reduction of the risk of adoption caused by the spreading of information on the benefits of the new technology (Bocquet et al., 2007). As Geroski (2000) underlined, according to these theories, learning, expectation and uncertainty are related to costs of knowledge. Indeed if knowledge transfer is costly, agents with little information will be uncertain about the benefit of a new technology. The uncertainty of a new adoption primarily depends on the lack of information or asymmetries among users (Mansfield, 1961).

As suggested by the epidemic approach, the uncertainty of new technology rent is a significant barrier to the diffusion of innovation. In the identification of the lead market, Beise (2004) emphasized the role of reputable first adopters in signalling the credibility of innovation that can further reduce the risk of adoption.

As a matter of fact, the so-called demonstration effect is an important mechanism of diffusion (Mansfield, 1968) and allows the epidemic diffusion of innovation.

In contrast to the epidemic approach, probit models (Davies, 1979; Karshenas and Stoneman, 1993) calculate the diffusion path ranking firms by their characteristics. These models cover the gap of epidemic theories that simplify reality because undervaluate that the adoption decision is a choice made by specific individuals or firms (Geroski, 2000).

This micro-foundation point of view assumes that adopters differ in some characteristics (such as firm size) that affect the profitability of adopting the new technology. These features could impact on other users' adoption costs.

Firms adopt the new technology as acquisition costs fall; these costs are assumed to fall over time. These costs can be recollected as the ones that a potential adopter has to pay to employ new technology. The higher they are, the slower the diffusion takes place.

As acquisition costs fall, the cumulative benefit distribution is mapped out as a diffusion path, where early adopters achieve high returns by adopting while late adopters achieve low returns (Karshenas and Stoneman, 1993).

As rank models suggest (Davies, 1979; Karhenas and Stoneman,1993) difference in adoption depends on firm characteristics such as size, status and financial resources.

Gerosky (2000) extended the discussion on the role of costs to probit models: searching costs, switching costs and opportunity costs affect adoption choices.

According to economics literature, switching costs are one of the main barriers to technology adoption (Menanteau and Lefebvre, 2010; Bunduchi and Smart, 2010).

They include the costs of scrapping existing fixed production factors, the restructuring of production and marketing organizations and the re-skilling of personnel.

In contrast to Antonelli (2006), we consider switching costs a distinct category of costs, separated from acquisition and searching costs (Bunduchi and Smart, 2010; Zhu et al., 2006) because they are more related to adopters than to technology itself. 
The idea of complementarities among adopters' assets is consistent with the concept of switching costs. In accordance with this idea the diffusion of new technology is prompted only if it fits with other choices of the firm.

The cost and difficulty in reorganizing the production process around the new technology (David and Greenstein, 1990; Goldfarb, 2005) represents an important barrier to innovation adoption. According to Goldfarb (2005) and Helpman and Trajtenberg (1996) the lack of complementary technologies is an important explanation of slow adoption rate.

The complementary view is coherent with the concept of preadaptation developed by Cattani (2005). He found that the availability of a prior experience and a pool of skill is fundamental to have a positive effect on technological performance.

A higher level of compatibility of innovation, defined as "the degree to which an innovation is perceived as being consistent with the existing values, past experiences, and needs of the receivers" (Rogers and Shoemaker, 1971; p. 22 ), allows a faster innovation diffusion (Teng et al., 2002). Switching costs are also affected by firms' existing competences and by the presence of dynamic capabilities (Teece and Pisano, 1994) that are considered the foundation of competitive advantage at the firm level and by the firm's ability to learn - i.e its "absorptive capacity" (Geroski, 2000). The organizations which control these capabilities will be more able to identify the most suitable innovation and adopt it: new technologies diffuse more rapidly in industries where these skills abound.

Finally, opportunity costs are created by previous investments and make the adoption of a new technology less convenient if its machinery has not yet been fully depreciated.

Antonelli (2006) identified in the irreversibility of capital goods a possible factor that delays the adoption and diffusion of a new technology. The duration of goods' economic life affects the diffusion process until "the variable costs of the production process with the old technology are lower than the total average cost obtained with the new technology" (p. 8).

Other literature thread stemming from game theory analyze the stock and order effect of diffusion of innovation (Reinganum, 1981; Fudenberg and Tirole, 1985; Karshenas and Stoneman, 1993; Erat and Kavadias, 2006). These studies focus on the strategic determinant of the adoption of innovation (Bocquet et al., 2007). According to Karshenas and Stoneman (1993) technological adoption depends on the number of previous adopters. Indeed, diffusion occurs because once a firm adopts a specific innovation at a certain time, its competitors find it profitable to adopt it after the cost of technology has sufficiently decreased (Erat and Kavadias, 2006). For this reason, according to the stock mechanism of diffusion, the benefit deriving from the acquisition of the marginal adopter decreases as the number of previous adopters increases. In stock models, the impact of past adoptions on the return to a marginal adopter results from endogenizing the output decisions of firms (Karshenas and Stoneman,1993). As firms acquire new technologies, their production costs fall, leading to changes in the output of firms and the industry, thereby affecting industry prices and the profitability of further adoption. 
According to Ireland and Stoneman (1985) and Fudenberg and Tirole (1985) the returns from adopting a new technology depend on the adopters' position in the order of adoption. The models gave practical insights to firms' adoption decision, as they take into account how much waiting is necessary before adopting the innovation.

In these models, the adoption choice is affected by technology characteristics and costs, considered to decrease overtime. These costs include the purchase of patents and licenses, configuration and installation costs and costs for technological assistance and consultancy support. Naturally, when a technology innovation is introduced it is in an unfavorable position compared to existing technology, as it is more expensive, thus posing an important barrier to the diffusion process (Menanteau and Lefebvre, 2010).

Gerosky also explained the phenomenon of "information cascades" where the diffusion is contingent with the information adopted by the very first adopters while the remainder of the diffusion is best described as herd-like behaviour. He also argued that when network externalities are present, they strengthen the information cascade effect. The diffusion process between competing technologies ideally consists of three phases: the initial choice between various technologies, the lock-in with the chosen technology and finally, the bandwagon effect induced by imitation. From this point of view, the S-shaped curve is one of the possible outcomes of the diffusion rather than the starting point of the analysis (Geroski, 2000).

The presence of an interaction network could affect the diffusion of innovation (Deroian, 2002; Teng et al., 2002; Antonelli, 2006). In fact, when a population of potential adopters interact with each other in order to form or confirm their opinion on a new technology, they are able to favour or impede the diffusion of innovation.

The network effect is also explained by the rise of institutional isomorphism among organizations. Indeed, according to the concept of the iron cage, the firm choice to adopt a new innovation is related to its need to receive legitimacy (DiMaggio and Powell, 1991). While early adopters of organizational innovations are commonly driven by a desire to improve performance, for later followers adoption provides legitimacy rather than improves performance (Meyer and Rowan, 1977).

At an aggregate level, the diffusion of innovation represents the outcome of organizational homogenization: since each member of the population is forced to adopt the innovation in order to reach legitimacy, the new technology spreads.

If a network already exists, the introduction of a new technology requires the network to form or shift its opinion on the innovation. Moreover it has been demonstrated that in markets with a higher level of social influence there is a degree of uncertainty concerning the new technology that affects the final success of innovation diffusion (Delre et al., 2010). Consequently, the network structure can strongly affect the diffusion rate. To encourage network effects it is important to promote the spread of information among potential users. Network effects can rise in presence of technology standards that simplify the interrelation among different technologies, or in presence of network externalities that increase the utility users 
gain from using a technology when the total size of the network or the availability of complementary goods increases (Hall and Khan, 2003).

The introduction of new technology also implies a change in existing relationships and routines in the network. Network transformation costs are another important barrier to new technology diffusion.

Table 1 summarizes the relevant barriers to diffusion of innovation classified through the essential review of main theoretical DOI research.

Tab. 1: Barriers to diffusion of innovations

\begin{tabular}{|c|c|c|c|}
\hline FOCUS & ADOPTERS & TECHNOLOGY & \multicolumn{1}{c|}{ NETWORK } \\
\hline $\begin{array}{c}\text { Theoretical } \\
\text { approaches }\end{array}$ & $\begin{array}{c}\text { Epidemic approach } \\
\text { Probit models }\end{array}$ & $\begin{array}{c}\text { Stock and Order } \\
\text { models }\end{array}$ & \multicolumn{1}{|l|}{ Information Cascade } \\
\hline $\begin{array}{c}\text { Barriers to } \\
\text { technology diffusion }\end{array}$ & $\begin{array}{l}\text { - Searching costs } \\
- \text { Learning costs } \\
- \text { Switching costs } \\
- \text { Opportunity costs }\end{array}$ & $\begin{array}{l}\text { - Cost of technology } \\
\text { - Network externalities } \\
\text { - Network transition costs } \\
\text { - Network development } \\
\text { costs }\end{array}$ \\
\hline
\end{tabular}

Source: Our elaboration

\section{Diffusion-oriented policies and barriers to new technologies diffusion}

Innovation management literature generally focuses on mission-oriented initiatives, and is still small and fragmented with regards to diffusion policies.

Ergas (1987) specified that the first priority in setting technology policies is to ease the constraints and rigidities that slow down the diffusion of new skills, technical capabilities and - therefore - technological innovation. In particular, diffusion oriented policies that are aimed at increasing the acquisition, the diffusion and the assimilation of a new technology should be oriented at reducing such diffusion barriers.

The conceptual framework here presented aims at linking policy instruments to the rigidities that impede diffusion process. Both the policy-makers, which are a technology supplier that wants to promote its own innovation and the government aiming at enhancing the public sector innovation, have a wide range of policy instruments to support technology diffusion.

As highlighted by the epidemic theory, information asymmetries constitute an important constraint to technology diffusion. Adopters should not decide to use a technology if its searching costs are too high.

In this case, policy intervention, in terms of information provision, is desirable. A wide range of private and public information policies, such as demonstration projects and advertising campaigns, publicly funded technology monitoring exercises that inform the industry of recent technology advances, public subsidy of consulting activities and so on (Stoneman and Diederen, 1994). 
Policy-makers might promote word of mouth communication or try to identify key actors in order to make them evangelical supporters (Geroski, 2000). In particular, the information flow generated by state government policy can help endusers make more informed choices (Moon and Bretschneider, 1997) between alternative technologies. In particular, Moon and Bretschneider (1997) suggest that governments have the role of promoting information flow: "fact sheets, the operation of consumer hot-lines, and the development of standardized testing procedures, rating systems, performance standards and guidelines [and demonstration of project results] - can help end-users make more informed choices among alternative technologies" (Brown et al., 1990; p. 125). The enhancement of the information flow is not the only means used to reduce adoption uncertainty. Another way is to set technology standards that allow the creation of information. In fact, technology standards are a solution to reduce the technological alternatives at the disposal of firms and limit their exposure to the risks of choosing the losing technology (David and Greenstein, 1990). In case of failure of a technological standard, however, the negative effects on adopters may be disproportionally high. Standards setting processes are sometimes also an important way to resolve the externalities which surround choice (Geroski, 2000).

The diffusion constraints represented by learning costs - considered by probit models - rise noticeably when knowledge transfer is costly and negatively related to an individual's capabilities. This dimension is strictly related to technology expectation and uncertainties, since agents will not acquire complete information if knowledge transfer is costly and will be uncertain about just what the new technology does and how to use it best (Geroski, 2000). Geroski (2000) suggested that while policies that improve the information flow make firms more aware of their opportunities, knowledge transfer policies make firms more capable of exploiting them.

Technical training and assistance or organizational ties can be promoted to reduce these uncertainties.

Government policies, for example, could enhance personnel cooperation by also providing personnel for potential adopters (Moon and Bretschneider,1997). Firms may need to acquire special skills to adopt new technology and, even in presence of such policy, could decide not to do so.

On the other hand, the funding of potential adopters could help reduce the barriers caused by high switching, opportunity and acquisition costs.

Financial flow includes monetary subsidies to potential adopters or nonmonetary activities such as policy assistance, policy direction, auditing, personnel exchange, counselling, technical communication and so on (Moon and Bretschneider, 1997). 
Tab. 2: The relationship between barriers to diffusion of innovation and diffusion policies

\begin{tabular}{|c|c|}
\hline Barriers to technology diffusion & Policies \\
\hline Cost of technology & $\begin{array}{l}\text { - Monetary subsidies for technology } \\
\text { acquisition }\end{array}$ \\
\hline Searching costs & $\begin{array}{l}\text { - Demonstration projects } \\
\text { - Advertising campaigns } \\
\text { - Monetary subsidies for consulting } \\
\text { - Technology monitoring } \\
\text { - Definition of technological standards } \\
\text { - Identification of key adopters }\end{array}$ \\
\hline Learning costs & $\begin{array}{l}\text { - Technical training } \\
\text { - Incentives for the formation of partnerships } \\
\text { between adopters and technology providers } \\
\text { - Personnel exchange and provision }\end{array}$ \\
\hline Switching costs & $\begin{array}{l}\text { - Assistance } \\
\text { - Technical communication } \\
\text { - Pre-competitive consortia }\end{array}$ \\
\hline Opportunity costs & $\begin{array}{l}\text { - Monetary subsidies for technology } \\
\text { substitution }\end{array}$ \\
\hline Network esternalities & $\begin{array}{l}\text { - Monetary subsidies for the network } \\
\text { externalities creation } \\
\text { - Public procurement }\end{array}$ \\
\hline Network transition costs & $\begin{array}{l}\text { Definition of technological standards } \\
\text { - Incentives for the formation of partnerships } \\
\text { between adopters and new partners }\end{array}$ \\
\hline
\end{tabular}

Source: Our elaboration

In truth, both subsidies, which encourage the building up of various types of human and financial capital, will stimulate competition (particularly that of new entrants). The effect of competition policy on technology diffusion is difficult to evaluate since there is no clear position in the literature about which market structure will best improve the diffusion path (Stoneman and Diederen, 1994).

In order to reduce negative externality the policy maker can tax the origin of the externalities or create specific ownership rights in order to internalize these costs. Diffusion policies are also effective in the case of positive externalities. It could occur that a specific technology should be diffused on a wide scale to become effective. In case of high network transformation costs, the adoption cannot take place or would take place too slowly if the first users don't find it profitable to adopt the new technology given the small size of the network at the date of the decision to adopt (Katz and Shapiro, 1986). 
Moreover, standard setting processes and administrative processes are sometimes an important way to resolve externalities (Geroski, 2000).

In line with the "information cascade" theory, "the timing of policy intervention may be at least as important as its substance" (p. 622). If the subsidy exists for a limited period of time it will perform better than if it were expected to last for a long period of time. Indeed in the latter case adopters may be tempted to delay their choice because they take the subsidy for granted (Stoneman and Diederen, 1994).

Furthermore, in presence of increasing returns, the subsidy may destroy the returns expectations of early adopters which decrease when the number of users increases.

Last but not least, mission-oriented policies could also indirectly enhance technology adoption. For instance, overcoming the dichotomy between generation and diffusion policy, Hahn and Yu (1999) proposed an integrated incentive system that contemplate both at the same time. The diffusion-based incentive system (DBIS) is designed to synchronize and balance the role of generation and mission oriented policy, considering the imperfection of the market and the cumulative effect of technological change.

In the next section, the previously presented conceptual framework will be illustrated in a real market situation in order to be more appealing and constructive.

\section{Diffusion policies of the Li-lon Battery in the automotive industry}

Lithium-ion (Li-Ion) batteries are expected to become the most popular battery for plug-in and full-battery electric vehicles (PHEVs and BEVs). Despite there being several types of batteries, including lead-acid and nickel-metal hydride batteries $(\mathrm{NiMH})$ that will continue to retain a considerable market share in the short term, lithium-ion batteries are expected to dominate the market by 2017 (Deutsche Bank, 2009). In particular, being lightweight, Li-Ion batteries can be made into large battery packs to be used in hybrid and electric vehicles and contain relatively high energy, allowing them to be used in a range of small consumer products such as cell phones, tablets and laptops. Another important characteristic of lithium is that it is reusable and therefore can be extracted from depleted batteries and recycled in new batteries.

Research activities in this field have been very intense, considering that about 7000 lithium-battery related patents (both U.S. and International patent) were issued during the 1997-2007 period.

The main battery manufacturers are concentrated in Asia, near manufacturing sites for battery dependent portable consumer products. Automotive batteries are one of the fastest-growing applications of Li-Ion technology: the transition from small, consumer-goods batteries to larger batteries for motor vehicles may well open the door for new entrants in the industry.

Lithium-ion batteries are the most suitable existing technology for electric vehicles, but there are many reasons why they did not completely diffuse in the 
automotive industry, delaying the spread of electric car. The first and strongest barrier to the diffusion of Li-Ion technology into automotive industry is its cost.

The cost of lithium battery is four to eight times that of lead acid and one to four times that of NiMH, the two main competing technologies (Nishino, 2010). This high cost represents a critical concern for its diffusion, as the cost of electric vehicles is still too high compared to their reduced technical performance (autonomy and speed limits). One of the main reasons for such high costs is that advanced battery manufacturing is still an infant industry whose technology and potential market remain highly uncertain (Canis, 2013).

Unlike lead-acid batteries, which are simply dropped into a vehicle's engine compartment and connected to the electrical system, a Li-Ion battery should be integrated with car technologies. In particular, the adopters should provide additional and critical proprietary technologies: in fact they are integrally involved in the design and production of Li-ion batteries for their vehicles. Moreover, the development of complementary technologies represents a cost for potential adopters that should be locked-in.

As a matter of fact, in their choice to implement an electric vehicle that run on Li-Ion batteries, automakers will sustain several costs: searching costs, linked to their capabilities to identify the leading technology in which to invest, learning and switching costs related to the development of complementary capabilities to improve the battery in the vehicle and opportunity costs related to the lock-in effect if they choose the wrong technology.

The weak diffusion of electrical vehicles - and then of the Li-Ion battery in the automotive industry- is also due to the high cost of network transformation. The substitution of the conventional combustion gasoline engine with electric vehicles requires not only a radical transformation of the automotive supply chain (Ernst et al., 2012) but also the building of charging stations and their infrastructures. These network changes should allow a positive externality that can permit a faster and effective diffusion of electric vehicles and -as a consequence- the demand for the related technology only when a critical mass has been reached

The Li-Ion battery represents one of the rival technologies in the automotive industry. For this reason its diffusion is enhanced by the growth of car electrification. Several countries are trying to stimulate the production and the sales of electric vehicles in order to reduce oil consumption, air pollution, and greenhouse gas emissions. These interventions indirectly support the diffusion of the Li-Ion battery. The United States appears to be very committed to seizing the opportunity to be a leader in the production of lithium-battery for vehicles, considering the many advantages this national industry has, such as research capacity, domestic automotive industry, a large market for vehicles and the support of government policies.

There are two ways to support the diffusion of Li-Ion batteries: the first is to directly support the battery value chain through specific policies aimed at reducing the costs of production and technology suitability; the second way is to encourage 
the production and the use of electric car, which would indirectly allow the diffusion of this battery as an alternative solution for car fuel supply.

The U.S. Congress first supported electric vehicles in 1976, establishing a demonstration project with the purchase of 7500 electric vehicles and the beginning of DOE (Department of Energy) R\&D program. It already recognized that the electrification of the automotive industry was possible only with the improvement and the diffusion of advanced battery technology. In spite of the various programs specifically committed to supporting the automotive industry that were developed throughout the years, the ARRA (American Recovery and Reinvestment Act of 2009) program had an immediate impact on the spread of Li-Ion technology and the transformation of the national advanced battery industry.

Among other activities, the ARRA provides federal financial support to develop a domestic lithium-ion battery supply chain for electric vehicles and afterwards to help the intra-firm diffusion of such technology.

In order to reduce the main barrier of Li-Ion battery diffusion, federal policies aim at supporting R\&D programs in order to reduce the costs and improve the performance of Li-Ion batteries, assessing new materials for manufacturing in order to offer cheaper technology that could contribute to reducing the final cost of electric vehicles.

Moreover, a Li-Ion battery cost breakdown is possible by reducing the cost of components and raw materials supplied from overseas. The DOE offered \$2.4 billion of funding to battery-related manufacturers, including auto manufacturers, battery material suppliers, and battery recycling companies. These funds helped establish U.S. manufacturing plants, which all played key roles across the value chain, including materials, components, and the production of cells and battery packs. The DOE has also offered $\$ 25$ billion in low-interest loans to battery companies (Lowe et al., 2010).

The Li-Ion battery diffusion has also benefitted from the positive effect of world policies. Governments in Japan, South Korea and China are providing similar incentives, trying to stimulate the Li-Ion battery supply chain and become the leader in the manufacturing of advanced automobile batteries.

Besides these programs, the U.S. government offers a $\$ 7,500$ tax incentive (Deutsche Bank, 2009; DOE, 2010; Komblut \& Whoriskey, 2010) to consumers in order to pay the higher purchase price for electric vehicles. There is a large consensus about the effect of these policies on battery diffusion, considering that the economies of scale could drive battery technology costs down (Lowe et al., 2010).

In order to reduce the uncertainty of potential adopters, several demonstration projects have been developed. Searching and learning costs could be reduced by means of grants for $\$ 400$ million to purchase several thousand PHEVs for demonstration purposes, as well as to fund workforce training related to transportation electrification (Canis, 2013). Moreover, the military sector has become a technology incubator for battery development. It has been an early adopter and supporter of domestic lithium battery production. On the basis of such reasoning, one of the ARRA grants has been awarded to Saft America (the leading 
French battery maker) for the application of the battery in the military sector. Hybrid buses represent another niche market where the United States excels and has the potential to continue its dominance over the lithium-ion batteries market (Lowe et al., 2010).

In order to overcome switching costs, the ARRA grants provided support to automotive firms to develop electric cars. Since 2007, five companies have received $\$ 8,4$ billion in loans to work on hybrid and electric vehicles. the Clinton administration in 1993 had already established the Partnership for a New Generation of Vehicles (PNGV), a public-private partnership between the federal government and the USCAR (U.S. council for Automotive Research), with the aim of developing advanced and efficient technologies.

As highlighted before, automakers provide additional and critical technologies that unite the battery's output with the vehicle's overall operation (Canis, 2013). Automakers are involved in the design and production of specific technology for their vehicles. Several automakers have partnerships or have entered joint ventures with battery manufactures. Japanese automakers prefer strong alliances (i.e. the battery for the Nissan Leaf are sourced from a partnership with NEC; Toyota has a battery join venture with Panasonic), while non-Japanese automotive OEMs tend to prefer weaker supply agreements. For example, U.S. automakers shop for batteries for particular models in order to reduce the risk of a dangerous lock-in with a specific supplier. An additional part of U.S. government efforts to develop and sustain national battery manufactures industry consists in the fact that the heavy weight of large Li-ion batteries for cars and light trucks makes it more cost-effective to assemble them near the motor vehicle assembly plants where they will be used, rather than transport them for thousands of miles.

The diffusion of electric vehicles also calls for the transformation of the automakers network and the development of specific infrastructures.

The design of the electricity grid and the charging infrastructure are key characteristics for developing the diffusion of electric vehicles. In fact, the federal government, as well as utility companies, see the "vehicle to grid" as a market driver for electric vehicles, and then battery diffusion. The ARRA funding provided grants for the installation of a charging station network with the goal of establishing 40 million smart meters (Environmental Leader, 2010). The participation of energy companies, particularly those involved in utilities, in such electrification is widespread. Several utility companies started partnerships with local governments or automakers not only in the United States but also in Europe. The diffusion of Li-Ion battery technology in electric car production is strongly dependent on the number of previous adopters. An "information cascade" effect can be realized in presence of positive externalities. The more people adopt electric cars based on Li-Ion batteries, the more this technology will spread. The bandwagon effect is sustained by national subsidies that provide tax incentives to consumers in order to pay the higher purchase price for electric vehicles. As highlighted by Perdiguero and Jiménez (2012) these incentives are of limited effectiveness, resulting in a weak increase in demand for hybrid vehicles. Indeed, vehicles with electric motors have a shorter 
range, which may cause some consumers to avoid purchasing them without government incentives. The main point is to identify the bottleneck in the electric car value chain, thus identifying and promoting the best technology.

Tab. 3: Barriers to and policies in favour of Li-Ion battery diffusion

\begin{tabular}{|c|c|}
\hline $\begin{array}{c}\text { Barriers to } \\
\text { Li-Ion battery diffusion }\end{array}$ & Policies \\
\hline Cost of technology & $\begin{array}{l}\text { - Public funds for all key players battery manufacturers' } \\
\text { value chain } \\
\text { - Public funds for R\&D }\end{array}$ \\
\hline Searching costs & $\begin{array}{l}\text { - Public funds for demonstration project } \\
\text { - Use of the technology in military sector and public } \\
\text { transportation }\end{array}$ \\
\hline Learning costs & - Public funds for workforce training \\
\hline $\begin{array}{l}\text { Switching \& Opportunity } \\
\text { costs }\end{array}$ & $\begin{array}{l}\text { - Partnerships (JV or supply agreements) between } \\
\text { battery and car manufactures } \\
\text { - } \text { ATVM loans for automotive companies to work on EVs } \\
\text { - Partnerships for a New Generation of Vehicles (PNGV) }\end{array}$ \\
\hline Network esternalities & - Tax incentives for consumer electric car purchase \\
\hline Network transition costs & $\begin{array}{l}\text { - Grants for the development of charging infrastructure } \\
\text { - Partnerships between utilities companies and car } \\
\text { manufacturers or local governments }\end{array}$ \\
\hline
\end{tabular}

Source: Our elaboration

As mentioned throughout the paper, battery costs are the key factor that will determine whether electric vehicles can ultimately be competitive and win market shares at the expense of conventional vehicles.

Despite this innovation trend, other additional technological advances are required in order for the battery to be widely applied to electric vehicles. For this reason, current policies regarding Li-Ion battery are more concentrated on stimulating R\&D rather than its diffusion. The US Department of Energy in 2011 has encouraged investments through its Office of Science in basic research that are channelled through the Massachusetts Institute of Technology (MIT). This has resulted in the development of a new material known as the "new nanostructured cathode" which can be applied to battery technology (Perdiguero and Jiménez, 2012).

Many venture capital start- ups are emerging in the U.S. lithium-ion battery market, many of which are based on licensed technology from U.S. national laboratories and universities. They are accelerating the technology transition from laboratory to mass production. Considering that battery technology requires further 
advances to address costs, range and recharging issues, the Li-Ion battery may not be the ultimate solution.

\section{Conclusions}

Literature has deeply analysed policies for the development of innovations, but concentrated much less on the policies for innovations diffusion. To fill this gap, the study highlights that an effective approach to the diffusion of a new technology should be based on a careful analysis of the diffusion barriers and on a set of policies that simultaneously acts on these barriers.

Diffusion policy should ease the constraints and rigidities that slow down the diffusion of new skills, technical capabilities and the later technological innovation. In particular, diffusion oriented policy aiming at increasing the acquisition, diffusion and assimilation of technology in an industry should be oriented at reducing diffusion barriers.

The framework presented in the paper analyses diffusion policies in terms of the barriers to the diffusion of innovation that each policy is able to reduce. These barriers consist of the costs that potential adopters should pay to adopt a new technology. From the review of the foremost studies on innovation management, we identified three main sources of costs: technology costs, adopter costs and network costs. Diffusion policies should be directed to specifically easing these barriers and supporting effective innovation diffusion.

The narrative case of the Li-Ion battery technology diffusion in the U.S. shows that both public and private policies are often focused on the reduction of such barriers.

The case provides a clear picture of the many bottlenecks that a new technology may encounter during its process of diffusion and conveys the sense of the multiple interventions that are required to sustain the diffusion of a critical innovation. In this respect the U.S. government is playing a crucial role in catalysing the process of LiIon battery innovation and diffusion. The ARRA package helped expand the national battery industry, reducing constraints to a wider adoption of Li-Ion battery in electric vehicles. Using a wide range of policies, the U.S. government played the role of technology sponsor and diffuser.

Moreover, it is worth noticing that in the battery technology field there exists a bi-directional and cyclical linkage between innovation and diffusion policies: policies aimed at technology generation could improve technology diffusion and vice-versa (Hahn and $\mathrm{Yu}, 1999$ ). In particular, R\&D or industrial policies could have a secondary but relevant effect on the Li-Ion battery technology diffusion (Stoneman and Diederen, 1994).

The implications of the paper are manifold. From a theoretical standpoint, the paper opens the path towards the deepening of a subject that is still little studied.

As a matter of fact, innovation management literature generally focuses on mission-oriented initiatives and is still small and fragmented as regards to diffusion 
policies. To the best of our knowledge, there are few works that specifically analyze or synthesize diffusion policy in the management field. Discussions on diffusion policy are often misplaced in final research implications.

Instead, the paper firstly provides a classification of the barriers to the diffusion of a new technology, providing a different perspective of theoretical studies on the diffusion of innovations. In addition, it proposes a theoretical framework that links the policies to support the dissemination of an innovation to the diffusion barriers for the first time.

For policy makers the study provides a conceptual tool to guide their choices in supporting the diffusion of relevant technologies, considering that the "diffusion oriented" paradigm has become a trend of some countries' technology policy.

In fact, Chiang (1991) highlighted that diffusion-oriented countries, such as Japan or Germany, have performed better economically than "mission-oriented countries" like France or the UK. The key notion of diffusion policy, which is focused on the acquisition, diffusion and assimilation of a new technology, is to turn a country into a "smart follower" by adopting a new technology instead of an innovation developer.

\section{References}

ANTONELLI C. (2006), "Diffusion as a Process of Creative Adoption", The Journal of Technology Tranfer, vol. 31, n. 2, pp. 211-226.

ARROW K.J. (1962), Economic welfare and the allocation of resources for invention, in GROVES H.M., The Rate and Direction of Inventive Activity: Economic and Social Factors, National Bureau of Economic Research, Princenton University Press, Princeton.

BAPTISTA R. (1999), "The diffusion of process innovations: A selective review. International", Journal of the Economics of Business, vol. 6, n. 1, pp. 107-129.

BASS F. (1969), "A new product growth model for product diffusion”, Management Science, vol. 15 , n. 5 , pp. $215-227$.

BEISE M. (2004), "Lead markets: country-specific drivers of the global diffusion of innovations", Research Policy, vol. 33, n.6, pp. 997-1018.

BOCQUET R., BROSSARD O., SABATIER M. (2007), "Complementarities in organizational design and the diffusion of information technologies: An empirical analysis", Research Policy, vol. 36, n. 3, pp. 367-386.

BROWN M.A., BERRY L., GOEL R. (1990), "Guidelines for Successfully Transferring Government-sponsored Innovations", Research Policy, vol. 20, n. 2, pp. 121-143.

BUNDUCHI R., SMART A.U. (2010), "Process innovation costs in supply networks: a synthesis", International Journal of Management Reviews, vol. 12, n. 4, pp. 365-383.

CAERTELING J.S., HALMAN J.I., DOREE A.G. (2008), "Technology commercialization in road infrastructure: how government affects the variation and appropriability of technology", Journal of Product Innovation Management, vol. 25, n. 2, pp. 143-161.

CANIS B. (2013), Battery Manufacturing for Hybrid and Electric Vehicles: Policy Issues, Congressional Research Service Reports, UNT Libraries Government Documents Department. 
CATTANI G. (2005), "Preadaptation, firm heterogeneity, and technological performance: a study on the evolution of fiber optics, 1970-1995", Organization Science, vol. 16, n. 6 , pp. 563-580.

CHIANG J.T. (1991), "From 'mission-oriented'to 'diffusion-oriented' paradigm: the new trend of US industrial technology policy", Technovation, vol. 11, n. 6, pp. 339-356.

CLARK G. (1984), Innovation diffusion: contemporary geographical approaches, Geo Books, Norwich.

DASGUPTA P., STONEMAN P. (2005). Economic policy and technological performance, Cambridge University Press, Cambridge.

DAVID P.A., GREENSTEIN S. (1990), "The Economics Of Compatibility Standards: An Introduction To Recent Research", Economics of innovation and new technology, vol. 1, n. 1-2, pp 3-41.

DAVIES S. (1979), The diffusion of process innovations. Cambridge University Press, Cambridge.

DELRE S.A., JAGER W., BIJMOLT T.H., JANSSEN M.A. (2010), "Will it spread or not? The effects of social influences and network topology on innovation diffusion", Journal of Product Innovation Management, vol. 27, n. 2, pp. 267-282.

DEROIAN F. (2002), "Formation of social networks and diffusion of innovations", Research Policy, vol. 31, n. 5, pp. 835-846.

DEUTSCHE BANK (2009). Autos \& auto parts Electric Cars: Plugged in 2. from http://www.db.com

DIMAGGIO P., POWELL WW. (1991). "The iron cage revisited: Institutional isomorphism and collective rationality in organizational fields", American Sociological Review, vol. 48 , n. 2, pp. 147-160.

ERAT S., KAVADIAS S. (2006), "Introduction of new technologies to competing industrial customers", Management Science, vol. 52, n. 11, pp. 1675-1688.

ERGAS H. (1987) Does technology policy matter?, in Guile B., Brooks H. (Eds.), Technology and Global Industry. National Academy Press, Washington DC.

ENRST C.S., ÖZEL F., DAVIES H., OLSCHEWSKI I., PIEPER M. (2012), "The Development of the E-Mobility Supply Chain in Europe - Results of the European Project ENEVATE"

ENVIRONMENTAL LEADER (2010). Global V2G Market to Reach $\$ 26.6$ B by 2020. Retrieved August 17, 2010.

FUDENBERG D., TIROLE J. (1985) "Preemption and rent equalization in the adoption of new technology", The Review of Economic Studies, vol. 52, n. 3, pp. 383-401.

GEROSKI P.A. (2000), "Models of technology diffusion”, Research policy, vol. 29, n. 4, pp. 603-625.

GOLDFARB B. (2005), "Diffusion of general-purpose technologies: understanding patterns in the electrification of US Manufacturing 1880-1930", Industrial and Corporate Change, vol. 14, n. 5, pp. 745-773.

GRILICHES Z. (1957), "Hybrid corn: An exploration in the economics of technological change", Econometrica, Journal of the Econometric Society, vol. 25, n. 4, pp. 501522 .

HALL B.H., KHAN B. (2003), "Adoption of new technology”, National Bureau of Economic Research Working Paper, Working Paper, n. 9730.

HAHN Y.H., YU P.I. (1999), "Towards a new technology policy: the integration of generation and diffusion", Technovation, vol. 19, n. 3, pp. 177-186.

HELPMAN E., TRAJTENBERG M. (1996), "Diffusion of general purpose technologies", Working Paper, n. 5773, National Bureau of Economic Research Cambridge, MA. 
IRELAND N.J., STONEMAN P.L. (1985), “Order effects, perfect foresight and intertemporal price discrimination", Recherches Économiques de Louvain/Louvain Economic Review, vol. 51, n. 1, pp. 7-20.

KARSHENAS M., STONEMAN P.L. (1993), "Rank, stock, order, and epidemic effects in the diffusion of new process technologies: An empirical model", The RAND Journal of Economics, vol. 24, n. 4, pp. 503-528.

KATZ M.L., SHAPIRO C. (1986). "Technology adoption in the presence of network externalities", The Journal of Political Economy, vol. 94, n. 4, pp. 822-841.

KELLY P.J. (1978), The Diffusion of Innovation in Science Education, Centre for Science Education, Chelsea College, London.

LOWE M., TOKUOKA S., TRIGG T., GEREFFI G. (2010), Lithium-ion Batteries for Electric Vehicles: THE U.S. VALUE CHAIN, Center on Globalization, Governance \& Competitiveness Duke University, Durham, NC.

MANSFIELD E. (1961), "Technical change and the rate of imitation", Econometrica: Journal of the Econometric Society, vol. 29, n. 4, pp. 741-766.

MEADE N., ISLAM T. (2006), "Modelling and forecasting the diffusion of innovation-A 25year review", International Journal of Forecasting, vol. 22, n. 3, pp. 519-545.

MENANTEAU P., LEFEBVRE H. (2000), "Competing technologies and the diffusion of innovations: the emergence of energy-efficient lamps in the residential sector", Research Policy, vol. 29, n. 3, pp. 375-389.

MEYER J.W., ROWAN B. (1977), "Institutionalized organizations: formal structure as myth and ceremony", American Journal of Sociology, vol. 83, n. 2, pp. 340-63.

MOON M. J., BRETSCHNEIDER S. (1997), "Can state government actions affect innovation and its diffusion?: An extended communication model and empirical test", Technological Forecasting and Social Change, vol. 54, n. 1, pp. 57-77.

MOWERY D. (1995), The practice of technology policy, in Stoneman P. (Ed.), Handbook of the Economics of Innovation and Technological Change, (Chapter 12), WileyBlackwell, New Jersey.

NISHINO H. (2010), Key Technology for EVs; Lithium-Ion Secondary Battery. Retrieved June 25, 2010, from http://mitsui.mgssi.com/issues/report/r1005j_nishino.pdf

NUTLEY S., DAVIES H., WALTER I. (2002), "Conceptual Synthesis 1: Learning from the Diffusion of Innovations", Working paper n. 10, ESRC UK Centre for Evidence Based Policy and Practice, Swindon.

PERDIGUERO J., JIMÉNEZ J.L. (2012), "Policy options for the promotion of electric vehicles: a review", working paper Institut de Recerca en Economia Aplicada Regional i Pública, pp. 2-43

REINGANUM J.F. (1981), "On the diffusion of new technology: A game theoretic approach", The Review of Economic Studies, vol. 48, n. 3, pp. 395-405.

ROGERS E.M., SHOEMAKER F.F. (1971), Communication of Innovations; A CrossCultural Approach, Free Press, New York.

ROGERS E.M. (1995), Diffusion of innovations, Free Press, New York.

ROMER P.M. (1994), "The Origins of Endogenous Growth", Journal of Economic Perspectives, vol. 9, n. 1, pp. 3-22.

STONEMAN P. (1976), Technological Diffusion and the Computer Revolution, Cambridge University Press, Cambridge.

STONEMAN P., DIEDEREN P. (1994), "Technology diffusion and public policy", The Economic Journal, vol. 104, n. 425, pp. 918-930.

TEECE D., PISANO G. (1994). "The dynamic capabilities of firms: an introduction", Industrial and corporate change, vol. 3, n.3, pp. 537-556. 
TENG J.T., GROVER V., GUTTLER W. (2002), "Information technology innovations: general diffusion patterns and its relationships to innovation characteristics", Engineering Management, IEEE Transactions, vol. 49, n. 1, pp. 13-27.

WARNER K.E. (1974), "The need for some innovative concepts of innovation: an examination of research on the diffusion of innovations", Policy Sciences, vol. 5, n. 4 , pp. 433-451.

ZHU K., KRAEMER K.L., GURBAXANI V., XU S.X. (2006), "Migration to open-standard interorganizational systems: Network effects, switching costs, and path dependency", MIS Quarterly, vol. 30, pp. 515-539. 
